\title{
Takotsubo syndrome with pulmonary embolism: a case report and literature review
}

\author{
Qi $\operatorname{Jin}^{\dagger}$, Qin Luo ${ }^{\dagger}$, Zhihui Zhao, Qing Zhao, Xue Yu, Lu Yan, Liu Gao and Zhihong Liu* (0)
}

\begin{abstract}
Background: Takotsubo syndrome (TTS) is an acute cardiac condition with reversible heart failure which is often triggered by psychological and physical stressful events. Although pulmonary embolism (PE) was reported as a trigger for TTS, the concurrence of TTS and PE has been rarely reported, let alone that triggered by PE. Here we describe a case of a postmenopausal female presenting with symptoms similar to myocardial ischemia, which may be caused by $\mathrm{PE}$, and review the available literature that may help clinicians with their practice to similar situations since no published guidelines are available.

Case presentation: An 86-year-old female was referred to the emergency department for unrelieved chest tightness, shortness of breath and back pain. Cardiac biomarkers were mildly elevated and electrocardiogram displayed pathologic Q-waves, ST-segment elevation and inverted T-waves. Unexpectedly, coronary angiography was in absence of obstructed coronary atherosclerosis or acute plaque rupture. Chest computed tomography illustrated multiple pulmonary emboli in bilateral pulmonary arteries. She had suffered from long-term right lower extremity pain and experienced a long railway journey with less activity. Both echocardiogram and cardiac magnetic resonance demonstrated regional hypokinesia of left ventricle. She received anticoagulant and diuretic therapies, three-month follow up after discharge revealed uneventful recovery without any pulmonary emboli or regional motion abnormalities, thus she was retrospectively diagnosed with TTS caused by PE.
\end{abstract}

Conclusion: TTS and PE are scarcely concurrent and PE can exert as a potential trigger for TTS. TTS is easily misdiagnosed, actively seeking possible risk factors of TTS is in favor of early diagnosis and timely intervention. TTS with PE is reversible, timely and effective treatments ensure the best possible outcome.

Keywords: Takotsubo syndrome, Pulmonary embolism, Literature review

\section{Background}

Takotsubo syndrome (TTS) is characterized by transient left ventricular systolic dysfunction without evidence of obstructive coronary artery disease or acute plaque rupture. Postmenopausal women account for about $90 \%$ of cases, women $>55$ years old have 4.8 times higher risks of developing TTS compared to

\footnotetext{
* Correspondence: zhihongliufuwai@163.com

${ }^{\dagger}$ Qi Jin and Qin Luo contributed equally to this work.

Center for Pulmonary Vascular Diseases, Fuwai Hospital, National Center for Cardiovascular Diseases, Chinese Academy of Medical Sciences and Peking Union Medical College, 167 Beilishi Road, Xicheng District, Beijing 100037,
} China

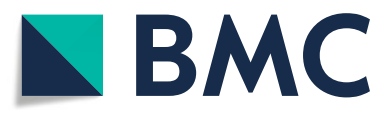

(๑) The Author(s). 2018 Open Access This article is distributed under the terms of the Creative Commons Attribution 4.0 International License (http://creativecommons.org/licenses/by/4.0/), which permits unrestricted use, distribution, and reproduction in any medium, provided you give appropriate credit to the original author(s) and the source, provide a link to the Creative Commons license, and indicate if changes were made. The Creative Commons Public Domain Dedication waiver (http://creativecommons.org/publicdomain/zero/1.0/) applies to the data made available in this article, unless otherwise stated. physically or emotionally stressful events and has similar clinical manifestations as acute coronary syndrome (ACS) [1, 2]. The pathogenesis of TTS is not well established, although pulmonary embolism (PE) has been listed as a potential contributor, TTS with $\mathrm{PE}$ is rarely described. Herein, we present a rare case of TTS triggered by PE which completely recovered within short time under anticoagulant and diuretic therapies. We also focus on the available case reports of TTS concurrent with PE since no treatment guidelines are available. This case report and literature review may promote better understanding of TTS and have great implications in clinical practice. 


\section{Case presentation}

An 86-year-old woman was referred to the emergency department (ED) for unrelieved chest tightness, shortness of breath and back pain for $6 \mathrm{~h}$ on November 7, 2016. Three hours before admission, she presented to her local hospital and was newly diagnosed with acute anterior myocardial infarction (MI), loading doses of aspirin and clopidogrel were orally taken but failed to relieve her symptoms. Five days prior, she had experienced chest tightness on exertion with shortness of breath and no back pain, and these symptoms resolved within a few minutes to two hours at rest and failed to draw her attention. Past medical history included previous pulmonary tuberculosis, besides, she had 40 years of smoking history but quit 16 years ago.

Physical examination revealed vital signs as follows: blood pressure 100/76 mmHg, heart rate 82 beats/min, respiratory rate $20 / \mathrm{min}$. The cardiopulmonary examination was unremarkable, and no peripheral edema was present. The routine laboratory tests at ED revealed troponin I (cTnI) was $0.041 \mathrm{ng} / \mathrm{ml}$ (normal reference range $0-0.02 \mathrm{ng} / \mathrm{ml}$ ), and creatine kinase-MB (CK-MB) was $6.54 \mathrm{ng} / \mathrm{ml}$ (normal reference range $0-4.99 \mathrm{ng} / \mathrm{ml}$ ). No abnormalities were observed in complete blood count, renal and liver function tests. Electrocardiogram (ECG) showed abnormal Q-waves in leads I, aVL and V2-V9, ST-segment elevation in leads V2-V9, biphasic T-waves in V2-V9 and negative T-wave in V1 (Fig. 1a).

Echocardiogram was performed at ED admission, showing normal tricuspid annular plane systolic excursion and right ventricular diameter of $19 \mathrm{~mm}$, an enlarged left ventricle (LV) of $53 \mathrm{~mm}$ at end-diastole with a reduced ejection fraction (EF) of 36\% and decreased motion of the left ventricular anterior, anteroseptal, anterolateral wall and apex, and mild tricuspid regurgitation was observed with an estimated pulmonary artery systolic pressure (PASP) of $51 \mathrm{mmHg}$. Acute anterior wall and high lateral wall MI was initially diagnosed, thus emergency coronary angiography (CAG) was performed (Additional file 1: Video 1-2). Stable coronary plaques without signs of acute plaque rupture or coronary dissection were seen in the left anterior descending branch and right coronary artery. She was then sent to and managed in the coronary care unit after CAG. Dynamic changes of blood biomarkers and arterial blood gas results were summarized in Table1. Unexpectedly, CAG and dynamic alterations of cardiac biomarkers and ECGs seemed to rule out the initial diagnosis (Fig. 1, Additional file 1: Video 1-2, Table 1). Repeat echocardiogram on Day 1 displayed a normal-sized LV with left ventricular anterior, anteroseptal and apical hypokinesia and a left ventricular $\mathrm{EF}$ of $41 \%$.

By detailly inquiring medical history again, many years of right lower extremity pain, weakness of bilateral lower limbs for half a year and inactivity in the train for $10 \mathrm{~h}$ half a month ago were complained of. Since D-Dimer was extremely high, lower extremity venous ultrasound was done on Day 2, indicating multiple thrombi in the right intermuscular vein, dilation of bilateral deep femoral vein and spontaneous echo contrast. The following chest computed tomography $(\mathrm{CT})$ illustrated multiple emboli in bilateral pulmonary arteries, calcified nodules in left upper

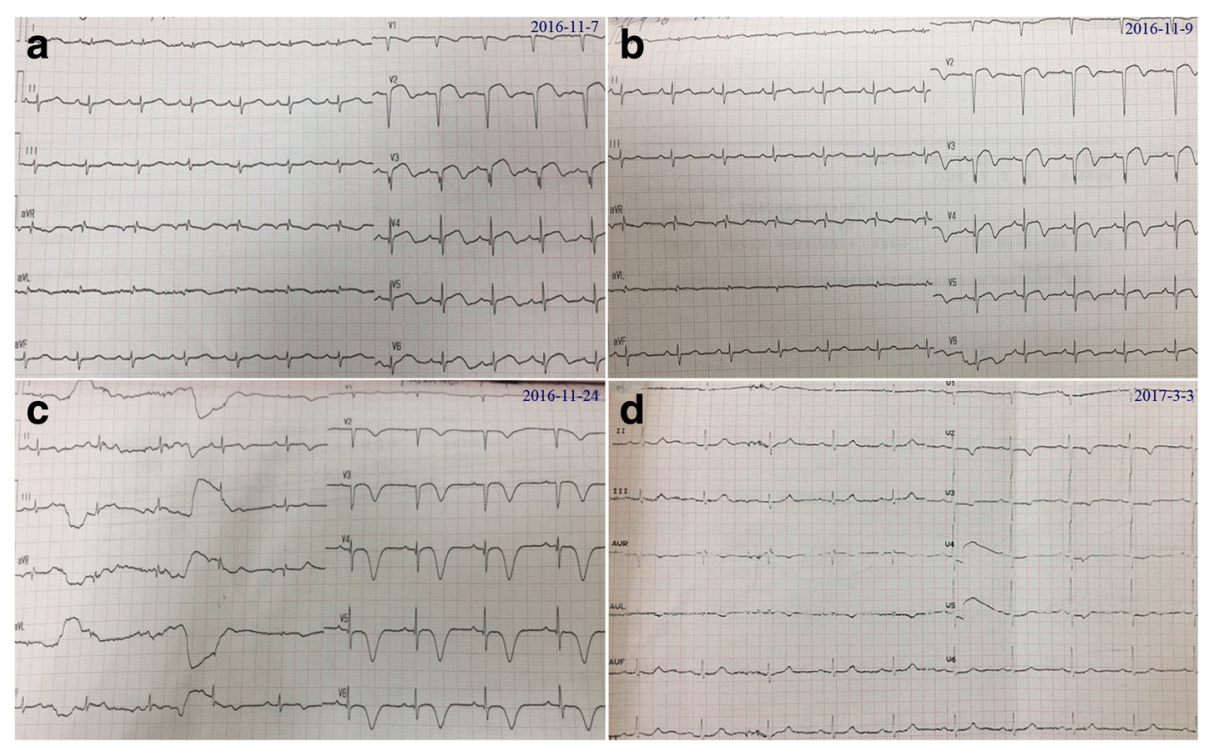

Fig. 1 Dynamic ECG changes from admission to 3 months follow-up. a ECG on admission; b ECG on Day 2 after admission; $\mathbf{c}$ ECG at discharge; d ECG at 3 months follow-up 
Table 1 Dynamic changes of biomarkers and blood gas results from admission to 3 months after discharge

\begin{tabular}{|c|c|c|c|c|c|c|}
\hline Date & $\begin{array}{l}16.11 .7 \\
\text { (on admission) }\end{array}$ & $\begin{array}{l}16.11 .7 \\
\text { (after CAG) }\end{array}$ & 16.11 .8 & 16.11 .9 & 16.11 .14 & $\begin{array}{l}3 \text { months } \\
\text { after discharge }\end{array}$ \\
\hline CK-MB (ng/ml) & $6.54(<4.99)$ & $5.22(<4.99)$ & $5.93(<4.99)$ & - & $1.25(<4.99)$ & - \\
\hline Myoglobin (ng/ml) & - & $27.22(<70)$ & $223.95(<70)$ & - & $24.01(<70)$ & - \\
\hline cTNI (ng/ml) & $0.041(<0.02)$ & $0.108(<0.15)$ & $0.067(<0.15)$ & $0.047(<0.15)$ & $0.033(<0.15)$ & $0.002(<0.15)$ \\
\hline D-Dimer (ug/ml) & - & $12(<0.55)$ & $10.28(<0.55)$ & $2.59(<0.55)$ & $1.77(<0.55)$ & $0.32(<0.55)$ \\
\hline NT-proBNP (pg/ml) & - & $5727.8(<300)$ & $4487.7(<300)$ & $7286(<300)$ & $3783.5(<300)$ & $255.9(<300)$ \\
\hline \multicolumn{7}{|l|}{ Blood Gases } \\
\hline Oxygen Flow & - & $3 \mathrm{~L} / \mathrm{min}$ & - & $3 \mathrm{~L} / \mathrm{min}$ & $3 \mathrm{~L} / \mathrm{min}$ & - \\
\hline $\mathrm{pH}$ & - & 7.41 & - & 7.48 & 7.43 & 7.44 \\
\hline pCO2 (mmHg) & - & 29 & - & 34 & 37 & 39 \\
\hline pO2 (mmHg) & - & 86.3 & - & 89 & 87 & 75 \\
\hline $\mathrm{SaO} 2(\%)$ & - & 97.8 & - & 99 & 99 & 95 \\
\hline
\end{tabular}

pulmonary lobe, posterior segment of the right upper lobe and the anterior basement of the lower lobe (Fig. 2).

Cardiac magnetic resonance (CMR) (Fig. 3a-c, Additional file 1: Video 3-4) on Day 7 demonstrated paradoxical systolic motion of anterior left ventricular wall and akinesis of apex with an EF of 43\%, and TTS could not be excluded. Filling defects in the right upper lobe and basal segments of the right lower lobe corresponded with pulmonary thromboembolism.

She received aspirin $100 \mathrm{mg}$ qd, clopidogrel $75 \mathrm{mg}$ qd, isosorbide dinitrate $10 \mathrm{mg}$ tid, atenolol $3.125 \mathrm{mg}$ bid, atorvastatin $20 \mathrm{mg} \mathrm{qn}$, nicorandil $5 \mathrm{mg}$ tid, furosemide $20 \mathrm{mg}$ qd and spironolactone $20 \mathrm{mg} \mathrm{qd}$ and enoxaparin $0.3 \mathrm{ml}$ qd on admission. Angiotensin converting enzyme inhibitors were not used due to low blood pressure. Dual antiplatelet therapy was terminated and enoxaparin was changed to $0.3 \mathrm{ml} \mathrm{q} 12 \mathrm{~h}$ while PE was suspected, and enoxaparin was switched to rivaroxaban $15 \mathrm{mg}$ bid after one week, the latter was used for three weeks and was adjusted to $15 \mathrm{mg}$ qd in consideration of her old age and bleeding risk. She was in a stable condition at 3 months follow-up after discharge, no chest tightness, chest pain or
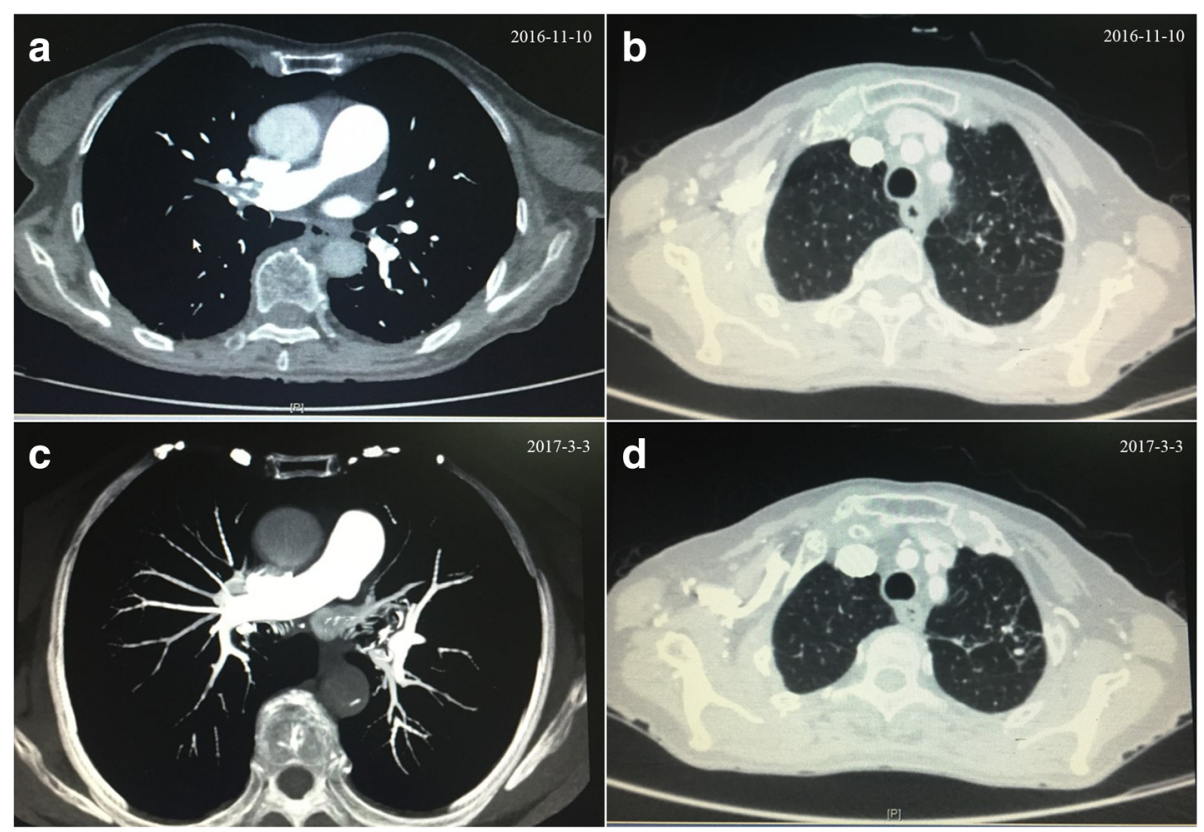

Fig. 2 Comparison of chest CT on Day 3 after admission ( $\mathbf{a}$ and $\mathbf{b}$ ) and at 3 months follow-up (c and $\mathbf{d}$ ) 


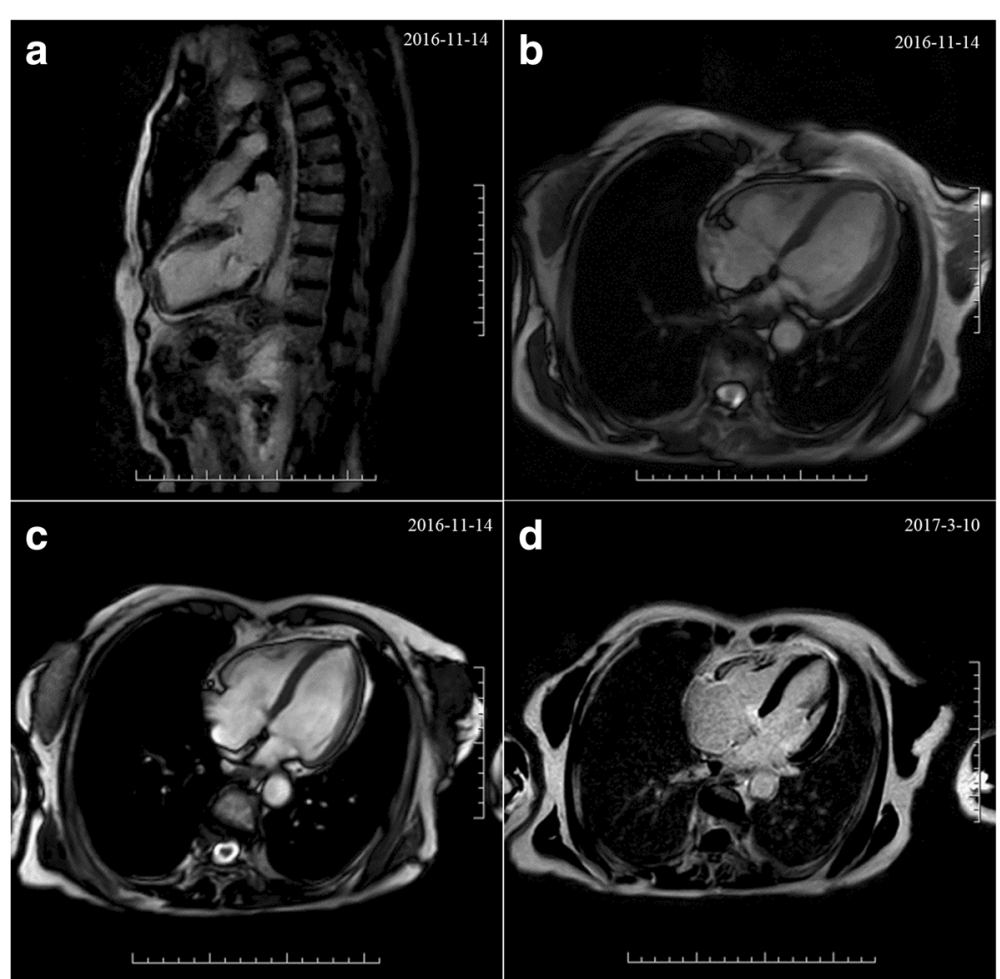

Fig. 3 Comparison of CMR on Day 7 after admission (a-c) and at 3 months follow-up (d)

shortness of breath were complained of. Serological biomarkers and blood gas results were within normal ranges (Table 1). Echocardiogram revealed normalsized LV with an EF of $68 \%$, mild aortic valve regurgitation and tricuspid regurgitation, but no regional wall motion abnormalities were detected (Fig. 4). No any evidence of PE was spotted in CT. CMR demonstrated improvement in left ventricular systolic function in comparison with the former (Fig. 3d, Additional file 1: Video 5-6). Hence, her final diagnosis was corrected as TTS with PE and bilateral deep venous thrombosis.

\section{Discussion and Conclusions}

TTS is an acute reversible heart failure syndrome which was first described in 1990 and mainly occurs

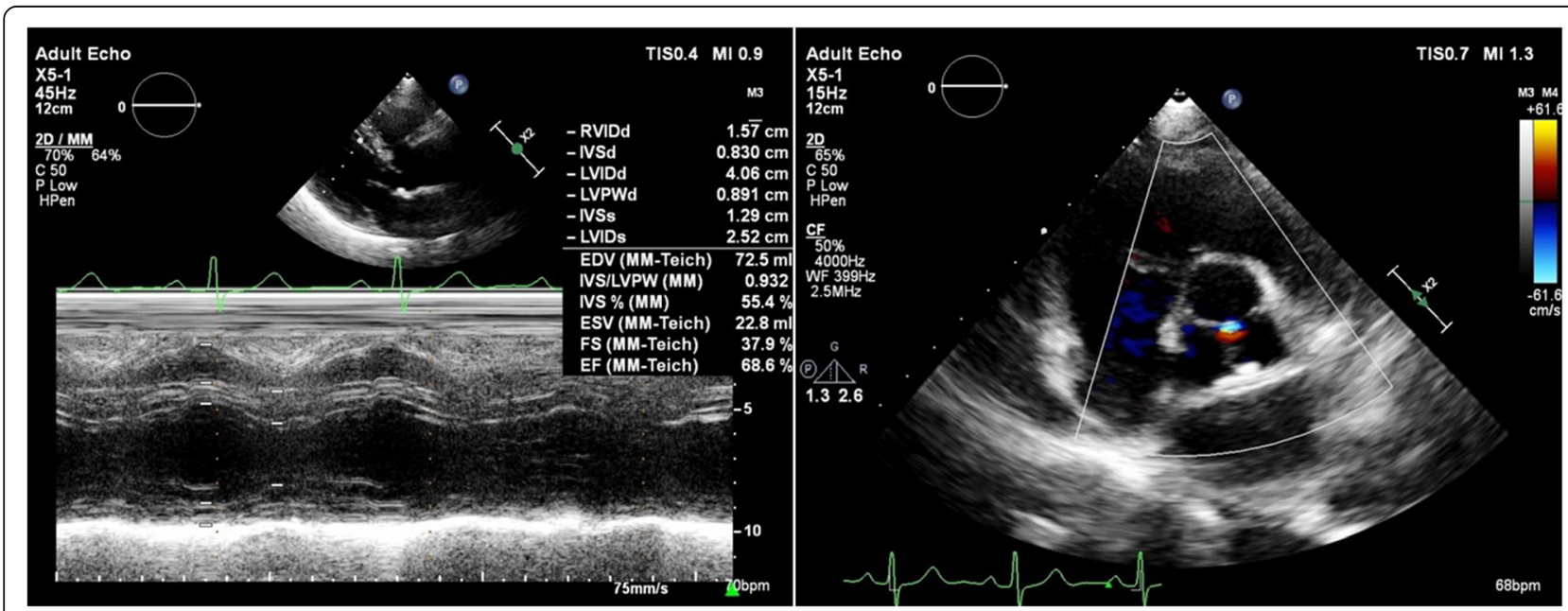

Fig. 4 Echocardiogram at 3 months follow-up, showing normal systolic function 
in postmenopausal women [3]. The pathological mechanism of TTS remains unclear, several possible theories have been postulated, such as catecholamine excess, coronary artery spasm, microvascular dysfunction and metabolic disturbance [2, 4].

Our patient is a postmenopausal woman, presenting with similar presentations to ACS. Abnormal ECG changes and elevated cardiac biomarkers on admission led to a suspected diagnosis of ST-elevation MI. However, urgent CAG along with dynamic ECG changes and biomarkers didn't support the aforementioned diagnosis. Both repeated echocardiogram and CMR confirmed transient hypokinesia of left ventricular apex and regional left ventricular wall motion abnormalities. Besides, CMR didn't support any signs of myocarditis or other cardiomyopathies. She made an uneventful recovery under treatments for three months without any elevated cardiac biomarkers, abnormal ECG changes and regional wall motion abnormalities. All in all, she was retrospectively diagnosed with TTS according to the Mayo Clinic diagnostic criteria, the most widely accepted criteria for clinical diagnosis of TTS [2].

TTS shares similar clinical presentations with ACS, thus it is quite easy to misdiagnose. Nevertheless, several significant differences exist between them. Near 90\% of the patients with TTS were elderly postmenopausal women, but women had a lower incidence of ACS than men in all ages [5]. CAGs of TTS patients lack culprit atherosclerotic coronary artery lesions. Besides, TTS exhibits milder increase of CK-MB and cTnI compared to MI, cTnI levels of our patient were slightly elevated and presented a gradual declining trend. NT-proBNP level in TTS was significantly increased (mean $>4000 \mathrm{pg} / \mathrm{ml}$ ), often 3-4times higher than that in ACS, reaching its peak value at $48 \mathrm{~h}$ after presentation [6,7], its levels in our patient peaked at $7286 \mathrm{pg} / \mathrm{ml} 2$ days after admission. It was demonstrated positive $\mathrm{T}$ waves in lead aVR and no negative $\mathrm{T}$ waves in lead V1 identified TTS with a sensitivity of $95 \%$ and a specificity of $97 \%$, compared with ACS, TTS possessed greater numbers of leads with negative $\mathrm{T}$-waves and greater maximal amplitude of negative T-waves [8]. Her ECG at discharge represented extensively deep inverted T-waves in V2-V6 and biphasic T-waves in leads I-II, most importantly, positive T-wave in lead aVR and no negative T-wave in lead V1 were observed.

$\mathrm{PE}$ is a fatal disease and is easily overlooked due to its nonspecific clinical presentation. Though D-Dimer and lower-extremity deep vein thrombosis (DVT) indicated high possibility of PE, no typical S1Q3T3 pattern was observed in ECGs of our patient, CT confirmed multiple pulmonary emboli in bilateral pulmonary arteries. Paradoxical embolism referring to an embolus that transits from right-to-left-sided cardiac chambers was considered, but no patent foramen ovale and thrombosis were seen in repeated echocardiography. Medical history indicated she might for a long period of time have suffered from DVT, a usual cause of PE. As D-Dimer levels dwindled, NT-proBNP levels reached a peak, positive $\mathrm{T}$ wave in lead aVR and no negative $\mathrm{T}$ wave in lead $\mathrm{V} 1$ appeared at her discharge. Thus, her PE may precede TTS, we regarded acute PE as a reversible cause of TTS. Its pathophysiological mechanism remains unclear, but extensive perfusion defect in lungs after PE was observed in lung perfusion scintigraphy, one pathophysiological hypothesis might be addressed to increased catecholamine levels during severe pain and elevated oxidative stress following perfusion defect within the lung.

PE was considered as a potential trigger for secondary TTS [4], but TTS with PE is rarely reported [9-14]. Herein, we retrospectively reviewed seven available case reports of patients with TTS and PE (Table 2). TTS with PE occurs frequently in older women who suffered from thrombotic diseases. All patients reported in literature were female, 6/ 7 patients were $>55$ years old. Four of them had a history of DVT, other three experienced pyelonephritis, malleolar fracture surgery and inactivity when on a long-haul flight respectively, the latter two are common causes of DVT. CK-MB, cTnI and cTnT were mildly elevated, not as much high as those in patients with ACS, dynamic changes of these cardiac biomarkers may assist in differentiating TTS with PE from MI. ECG abnormalities were reported to be present in $>95 \%$ of TTS patients during the acute phase, they alone were not sufficient to distinguish TTS with PE from ST-segment elevation MI [3], ECGs in all reviewed cases displayed non-specific ST-T changes. Urgent CAG is a useful tool to rule out MI, no culprit coronary arteries were found in all reviewed patients. Echocardiogram or left ventriculogram should be considered first to verify suspected TTS since all reported cases showed transient hypokinesia or akinesia of regional wall motion. Anticoagulants, diuretics and $\beta$-blockers may be effective, and all patients got uneventful recovery with improvements in systolic function, indicating reversible manifestation and good prognosis of patients with coexistent TTS and PE.

TTS and PE are scarcely concurrent, here we present the first case of TTS caused by PE in China and for the first time review available similar literature. TTS with PE is easily misdiagnosed, clinicians should actively seek possible risk factors such as DVT for early diagnosis and timely intervention. TTS with PE is reversible, timely and effective treatments to eliminate the causes ensure the best possible outcome. 
$\begin{array}{ll}\text { Jin et al. BMC Cardiovascular Disorders } & \text { (2018) 18:229 }\end{array}$

Page 6 of 8

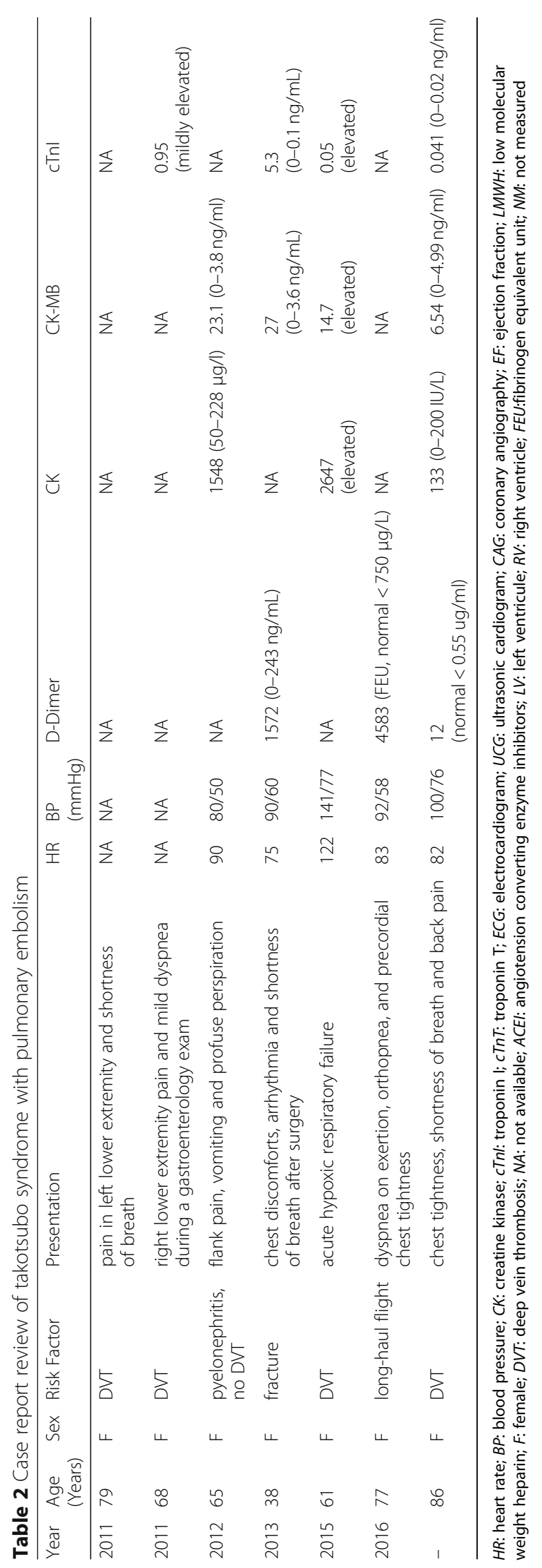




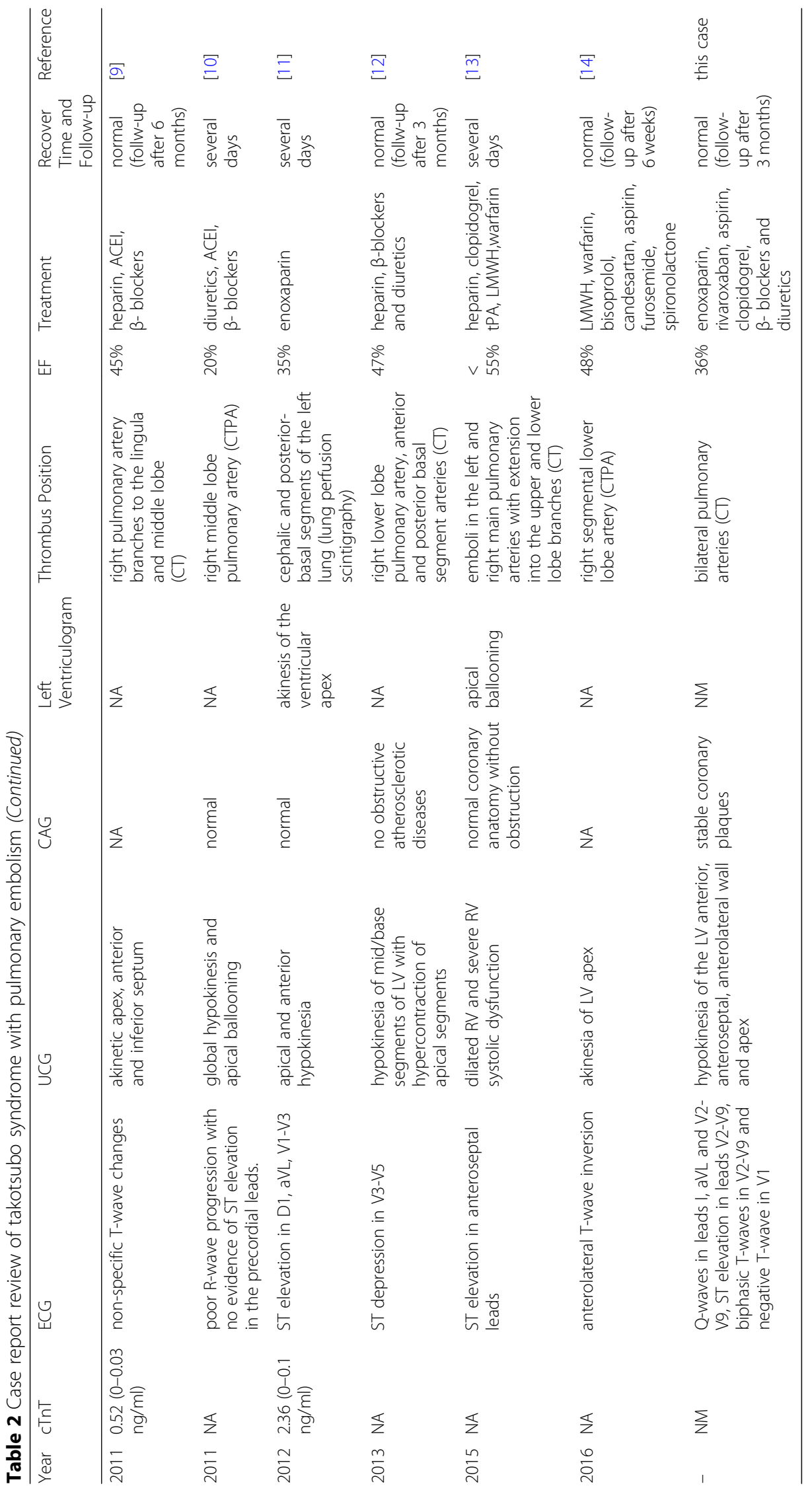




\section{Additional file}

Additional file 1: Representative CAG and CMR. (PPTX 87696 kb)

\section{Abbreviations}

ACS: Acute coronary syndrome; CAG: Coronary angiography; CK-MB: Creatine kinase-MB; CMR: Cardiac magnetic resonance; CT: Computed tomography; DVT: Deep vein thrombosis; ECG: Electrocardiogram; ED: Emergency department; EF: Ejection fraction; LV: Left ventricle; MI: Myocardial infarction; PASP: Pulmonary artery systolic pressure; PE: Pulmonary embolism; Tnl: Troponin I; TTS: Takotsubo syndrome

\section{Acknowledgements}

This case report was supported by ward doctors and nurses in acquisition, analyzing and interpretation of data.

\section{Funding}

This work was supported by the National Precision Medical Research Program of China (2016YFC0905602)

\section{Availability of data and materials}

All data generated or analysed during this study are included in this manuscript and its Additional files.

\section{Authors' contributions}

$J Q, L Q, Z Z H$ and ZQ collected data, JQ and LQ did the literature review and drafted the manuscript. YX, YL and GL followed up the patient. LZZ corrected the manuscript. All authors read and approved the fina manuscript.

\section{Ethics approval and consent to participate}

Not applicable. Study approval was not necessary as this is a case report and consent for publication was taken from the patients.

\section{Consent for publication}

Written informed consent was obtained from the patient for the publication of this case report. A copy of the written consent is available for review by the Editor-in-Chief of this journal.

\section{Competing interests}

The authors' declare that they have no competing interests.

\section{Publisher's Note}

Springer Nature remains neutral with regard to jurisdictional claims in published maps and institutional affiliations.

Received: 11 August 2018 Accepted: 13 November 2018

Published online: 10 December 2018

\section{References}

1. Deshmukh A, Kumar G, Pant S, Rihal C, Murugiah K, Mehta JL. Prevalence of Takotsubo cardiomyopathy in the United States. Am Heart J. 2012;164(1):66-71.

2. Ono R, Falcao LM. Takotsubo cardiomyopathy systematic review: pathophysiologic process, clinical presentation and diagnostic approach to Takotsubo cardiomyopathy. Int J Cardiol. 2016;209:196-205.

3. Lyon AR, Bossone E, Schneider B, Sechtem U, Citro R, Underwood SR, Sheppard MN, Figtree GA, Parodi G, Akashi YJ, Ruschitzka F, Filippatos G, Mebazaa A, Omerovic E. Current state of knowledge on Takotsubo syndrome: a position statement from the taskforce on Takotsubo syndrome of the heart failure Association of the European Society of cardiology. Eur J Heart Fail. 2016;18(1):8-27.

4. Prasad A, Lerman A, Rihal CS. Apical ballooning syndrome (Tako-Tsubo or stress cardiomyopathy): a mimic of acute myocardial infarction. Am Heart J. 2008;155(3):408-17.

5. Andreotti F, Marchese N. Women and coronary disease. Heart. 2008; 94(1):108-16.

6. Nguyen TH, Neil CJ, Sverdlov AL, Mahadavan G, Chirkov YY, Kucia AM, Stansborough J, Beltrame JF, Selvanayagam JB, Zeitz CJ, Struthers AD,
Frenneaux MP, Horowitz JD. N-terminal pro-brain natriuretic protein levels in takotsubo cardiomyopathy. Am J Cardiol. 2011:108(9):1316-21.

7. Sharkey SW, Maron BJ. Epidemiology and clinical profile of Takotsubo cardiomyopathy. Circ J. 2014;78(9):2119-28.

8. Kosuge M, Ebina T, Hibi K, Tsukahara K, Iwahashi N, Gohbara M, Matsuzawa Y, Okada K, Morita S, Umemura S, Kimura K. Differences in negative T waves among acute coronary syndrome, acute pulmonary embolism, and Takotsubo cardiomyopathy. Eur Heart J Acute Cardiovasc Care. 2012;1(4): 349-57.

9. Challa S, Ganji JL, Raizada A, Najib MQ, Panse PM, Chaliki HP. Takotsubo cardiomyopathy in a patient with pulmonary embolism. Eur J Echocardiogr. 2011;12(10):E39

10. Yu VY, Leitman DA, Graybeal TB, Cox CW. Subsegmental pulmonary embolus as a precipitating factor for takotsubo cardiomyopathy. Radiol Case Rep. 2011;6(3):531.

11. Fedele F, Gatto MC. Pulmonary embolism in a patient with apical ballooning syndrome. J Cardiovasc Med. 2012;13(1):56-9.

12. Lee SH, Kim DH, Jung MS, Lee JW, Nam KM, Cho YS, Jeong JH. Invertedtakotsubo cardiomyopathy in a patient with pulmonary embolism. Korean Circ J. 2013;43(12):834-8.

13. Sudhakar D, Pelton J, Bentz H, Posligua W, Pham D, El-Refai MO, Paniagua D, Jneid $H$, Denktas A. An unusual case of acute pulmonary embolism presenting with st elevation and apical ballooning syndrome. J Gen Intern Med. 2015:30:S361.

14. Ioannou A, Tanner S, Missouris CG. Takotsubo cardiomyopathy after acute pulmonary embolus. J Emerg Med. 2016;51(3):e55-6.

\section{Ready to submit your research? Choose BMC and benefit from:}

- fast, convenient online submission

- thorough peer review by experienced researchers in your field

- rapid publication on acceptance

- support for research data, including large and complex data types

- gold Open Access which fosters wider collaboration and increased citations

- maximum visibility for your research: over $100 \mathrm{M}$ website views per year

At $\mathrm{BMC}$, research is always in progress.

Learn more biomedcentral.com/submissions 